\title{
Occupational Health Nurses' Activity after General Health Examination for Workers ${ }^{\mathrm{a}}$
}

\author{
Masaiwa INOUE
}

\begin{abstract}
Department of Hygiene, Yamaguchi University School of Medicine, 1-1-1, Minamikogushi, Ube-City, Yamaguchi, Japan
\end{abstract}
Received July 3, 2006 and accepted October 10, 2006

\begin{abstract}
In this study, the present condition of occupational health nurse's role after performing general health examination was surveyed. Questionnaires were mailed to 41 companies, and returned questionnaires from 24 of them were analyzed. Although general health examination results were reported to all workers individually in $100 \%$ of companies, physician's opinion regarding the examination results were obtained in $86 \%$ of companies with part-time physicians comparing with $100 \%$ of those with full-time physicians. Health care support related to the examination results were performed by $90 \%$ of occupational health nurses and $70 \%$ of physicians in companies which employed full-time physicians, but by $\mathbf{1 0 0 \%}$ of occupational health nurses and $\mathbf{5 0 \%}$ of physicians in those which employed part-time physicians. In companies with part-time physicians, $64 \%$ of occupational health nurses played roles in submitting reports to Labor Standard Inspection Office, but only $30 \%$ of occupational health nurses did it in those with full-time physicians. These results show that occupational health nurses working in companies with part-time occupational health physicians were more active in providing health care for workers after general health examination than occupational health nurses working in those with full-time occupational health physicians.
\end{abstract}

Key words: Occupational health nurse, General health examination, Health care, Company

\section{Introduction}

In Japan, an employer is obligated to perform a general health examination (GHE) for workers in accordance with the Occupational Safety and Health law. The GHE system is composed of several types of health check-ups. A worker, who starts to be engaged in a company, should undergo the GHE assigned for a new employee. After that, the worker undergoes the GHE once a year periodically. Health examination for workers having a business trip to abroad for a duration of more than 6 months is also included in the GHE system. The purpose of the GHE system is to maintain proper work ability preventing life-style related disease. Items included in the GHE are considered in the law as a minimum requirement. Most of the items are relating to life-style disease, such as body weight, blood pressure, lipid

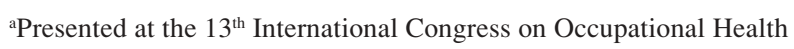
Services, November 30 - December 3, 2005, Utsunomiya, Japan. test, and glucose test. According to a report on GHE results summary from ministry of health, labor and welfare, almost half of the workers have abnormal findings ${ }^{1)}$; this is one of the most important issues to be solved in occupational health field.

In recent years, health care matters after completion of the GHE are considered seriously. The ministry reported a guideline for the concerned employers to take specific measures after the GHE. As in the guideline, it is also necessary for the employer to obtain physician's opinion regarding the GHE results and to provide health care support accordingly. The actual health care after GHE is provided by occupational health nurses (OHNs), especially in smallscale companies. In an international symposium on $\mathrm{OHN}$ expertise it has been reported that OHNs' knowledge and expertise is a value added commodity which will benefit the worker, company and society ${ }^{2}$. Research on working conditions for occupational health nurses shows that they need more organized support to improve health management 
in companies ${ }^{3)}$. In a study on occupational health nurses' role it has been proposed that advanced education programs for OHN should be introduced systematically ${ }^{4)}$.

There is a little information on OHNs activity and role regarding GHE related health care. OHNs activity will be more important in the future in occupational health field because the number of small-scale companies has increased during the recent years under the economic reconstruction phenomenon in Japan. Therefore, in this study, the present condition of OHN's role after performing GHE was surveyed and compared among the companies employing full-time occupational health physicians (OHPs) and those employing part-time OHPs to promote occupational health quality in small-scale companies.

\section{Materials and Methods}

This survey was conducted in Yamaguchi prefecture, which comparing with other prefectures in this country is a middleclass area with different type of industries and also fishing and agrarian villages.

Questionnaires including items on OHN's role after GHE were mailed to 41 companies employing OHNs, who belonged to the Occupational Nurse Research Association in Yamaguchi prefecture. The number of workers belonging to the individual company varied broadly from 100 to 2000 . In a cover letter asking for participation in the survey, we requested an answer to the questions from OHNs of the corresponding companies. OHNs, giving consent, recorded answers in an official postcard using only numbers or marks, and returned by mail without sender's name. The cover letter included notes that the confidentiality would be maintained and the use of data obtained would be confined to the survey. The questionnaires comprised items related to occupational health activity issues, such as returning of GHE results to workers, health care support for workers, and health committees' function. The type of company was not asked as the possibility of specifying the company could not be excluded by using the answers. Answers were returned by 25 companies but those from 24 were included in the analysis, as one questionnaire from a health examination agency was found unsuitable. In this survey, an OHN was defined as a nurse who was employed by a company and worked as an occupational health staff regularly.

The analysis was performed in a comparison between companies with full-time OHPs and those with part-time OHPs. The proportions of OHN's participation were compared between these two groups of companies, and chi- square tests were used to determine the statistical significance, which was considered to be $p<0.05$.

\section{Results}

Among the 24 companies included in the analysis, there was no company which did not perform the GHE. Occupational physicians were assigned in all companies, but there were 14 companies which assigned OHP as a parttime employee. Although the GHE results were reported to all workers individually in $100 \%$ of companies, physician's opinion regarding GHE results were obtained in $86 \%$ of companies with part-time OHPs comparing with $100 \%$ of those with full-time OHPs.

The proportions of companies which answered that healthrelated information according to GHE results sent back to workers were $90 \%$ in companies employing full-time OHPs and $100 \%$ in companies with part-time OHPs. A medical recommendation for re-examination and close examination of workers with abnormal findings was made, if necessary, in all companies surveyed. Health care support related to GHE results were performed by $90 \%$ of OHNs and $70 \%$ of OHPs in companies which employed full-time OHPs, but by $100 \%$ of OHNs and $50 \%$ of OHPs in those which employed part-time OHPs. GHE result data were kept and maintained by OHNs in $86 \%$ and $80 \%$ of companies with part-time OHPs and full-time OHPs, respectively. There was a significant difference in the proportions of OHNs who took part in health committee issues, $71 \%$ and $20 \%$ in companies with part-time OHPs and full-time OHPs, respectively $(p<0.05)$. In companies with part-time OHPs, $64 \%$ of OHNs played roles in submitting reports to Labor Standard Inspection Office, but only $30 \%$ of OHNs did it in those with full-time OHPs.

\section{Discussion}

The present survey found that the actual activities and roles of OHNs were not the same in companies with parttime OHPs and full-time OHPs. These findings might reflect the difference in matters the companies demanded from their OHNs. In respect to health care support for workers according to GHE results, although most OHNs enforced the task regardless of OHPs employment situation, 30\% of full-time OHPs and 50\% of part-time OHPs were not involved in this. Subsequently, companies who did not employ fulltime OHPs might demand mainly from their OHNs to provide occupational health support regarding with GHE. The results of this study also show that $100 \%$ of OHNs in companies 
Table 1. Comparison of $\mathrm{OH}$ activities between companies employing a full-time $\mathrm{OHP}$ and those employing a part-time $\mathrm{OHP}$

\begin{tabular}{|c|c|c|c|c|c|}
\hline \multirow[t]{2}{*}{ Items of $\mathrm{OH}$ duties } & \multicolumn{2}{|c|}{$\begin{array}{l}\text { Company with full-time-OHP } \\
\qquad(\mathrm{n}=10)\end{array}$} & \multicolumn{2}{|c|}{$\begin{array}{l}\text { Company with part-time-OHP } \\
\qquad(\mathrm{n}=14)\end{array}$} & \multirow[t]{2}{*}{$p$ value } \\
\hline & Number & $(\%)$ & Number & $(\%)$ & \\
\hline GHE results reported to workers & 10 & 100 & 14 & 100 & ns \\
\hline Physician's opinion regarding GHE results obtained & 10 & 100 & 12 & 86 & ns \\
\hline Health-related information sent to workers & 9 & 90 & 14 & 100 & ns \\
\hline Medical recommendation performed & 10 & 100 & 14 & 100 & ns \\
\hline Health care support performed by OHNs & 9 & 90 & 14 & 100 & ns \\
\hline Health care support performed by OHPs & 7 & 70 & 7 & 50 & $\mathrm{~ns}$ \\
\hline GHE result data kept and maintained mainly by OHNs & 8 & 80 & 12 & 86 & ns \\
\hline Participation of OHNs in health committee issues & 2 & 20 & 10 & 71 & 0.038 \\
\hline Report submission by OHNs to Labor Standard Inspection Office & 3 & 30 & 9 & 64 & ns \\
\hline
\end{tabular}

OH: Occupational Health; OHP: Occupational Health Physician; OHN: Occupational Health Nurse; GHE: General Health Examination; ns: not significant.

that employed part-time OHPs engaged themselves in health care support.

As to differences in the role of OHNs depending on the company characteristics, OHNs' participation in health committee needs to be mentioned specially. Health committees in the companies are the most important organizations to decide issues on occupational health. In Occupational Safety and Health law, OHPs are obligated to attend the meeting, but OHNs are not. Seventy-one percent of OHNs were found to take part in the committee issues in companies with part-time OHPs, which might indicate that OHNs in those companies played a role in participating the meetings instead of OHPs. A similar finding was shown also in our previous study ${ }^{5)}$.

As to whether OHNs played roles in health care support for workers after GHEs, $100 \%$ of OHNs in companies with part-time OHPs did the same while it was $90 \%$ in those with full-time OHPs. These findings demonstrate a potentially important role for OHNs in the activities after GHE especially in companies who employed only part-time OHPs. However, the OHNs' role could not be evaluated sufficiently because there are very few reports on present conditions of $\mathrm{OHN}$ activity related to GHE issues in Japan. One of the reasons for this seems to be that the role of OHN is not supported by Occupational Safety and Health law, which was also indicated in our previous study ${ }^{5}$. In that report, we suggested that current conditions in occupational health should be frequently reported to promote active discussions regarding helath care among occupational health-related staffs including OHNs and company managers. OHNs with appropriate knowledge and skills may implement GHE-relating issues.

Although there are some reports on OHNs' activity and roles in their companies ${ }^{3,4,6)}$, most of those concern general duties for OHNs and few studies are found to focus on duties after performing GHE. In the present survey, OHNs' tasks after GHE were centered and compared between the two types of companies whether the OHP was employed as fullor part-time. In this respect, the present survey has a notable feature.

However, there are several limitations to this survey. In the present study, the data were analyzed in a comparison between companies with part-time OHPs and full-time OHPs, and only one of the surveyed items showed significant difference (the proportions of participation in health committee meetings). This might be due to small sampling size. Two groups compared in this survey consisted of 14 companies with part-time OHPs and 10 companies with fulltime OHPs, which were from only one prefecture in Japan. Although the present result may not be generalized completely, but as the surveyed area has both characteristics of developed and urban regions, so the findings seem to be representative of the country.

Secondly, the response rate to the questionnaire sent by mail was not so high (58.5\%). In two other surveys on OHNs' activities performed in Japan, response rates were found to be $49.7 \%$ and $48.9 \%{ }^{6,7)}$. In this study, almost half of companies denied to cooperate. In the companies not responding to this survey, different situations might be present in the occupational health field.

Thirdly, the type of companies was not investigated in the questionnaire not to specify the company in this survey. Therefore, the current conditions of OHNs in this survey could not be analyzed according to the type of companies; but if classified the analysis might be not meaningful as the company number would become too small. Worker's age and sex were also not investigated. The reason was almost 
same with a fear of decrease in the response rate because companies seemed unlikely to submit their internal characteristic data.

All companies surveyed in the present study had appropriate occupational heath system in their organization and they performed a medical recommendation for re- or close examination which is not obligated under the law. However, there seemed to be some differences in OHNs' activity among the companies depending on the employment situation of OHPs. OHNs employed in companies with parttime OHPs took more responsibilities in occupational health issues than OHNs employed in those with full-time OHPs did. In particular, there was a significant difference in the proportions of OHNs' participation in health committee issues between companies with part-time OHPs $(71 \%)$ and those with full-time OHPs (20\%), also showing a difference in OHNs' roles in those companies. This finding indicates the importance of OHNs in occupational health system concerning companies especially with part-time OHPs.

The problem of occupational health system in companies with part-time OHPs might be associated with the present condition in Japanese society. In Japan, a long period has passed since serious economic recession started. Under the present weakened economic situation, it is anticipated that large companies will scale down in the number of employees and that a smaller related company will be created as a result of restructuring. According to Occupational Safety and Health law, a company having more than 1,000 employees must employ a full-time occupational health physician, and a company with less than 1,000 , but more than 50 employees, is required to appoint an occupational health physician but not necessarily on full-time basis. It is predicted that smaller size companies which are not obligated to employ a fulltime OHP might increase in the near future. In consequence the role of OHNs will be remarkable to maintain occupational health system in their companies.

In addition, the importance of OHNs' role in companies should be emphasized from the viewpoint of opportunity to contact with workers. While OHNs work 5 or $6 \mathrm{~d}$ in a week regularly in their companies, part-time OHPs rarely do so in the companies. According to the law, there is no regulation defining how many days per month is required for a parttime OHP to work at the company. Indeed, the frequency of working days for part-time OHPs in companies varied from $2 \mathrm{~d}$ per year to $2 \mathrm{~d}$ per week, according to our previous survey ${ }^{5}$. Under the present occupational health conditions, OHNs have become even more involved as key professionals in occupational health fields because they are familiar with employees' affairs and can suggest health care properly for workers.

In conclusion, this survey results show that OHNs working in companies with part-time OHPs were more active in providing health care for workers after GHE than OHNs working in those with full-time OHPs. This finding suggests that OHNs in companies with part-time OHPs took more responsibility to maintain health care support for workers than in those with full-time OHPs. In the future, OHNs, particularly those working with part-time OHPs, will have an important role in occupational health activity and in developing $\mathrm{OH}$ services for their companies.

\section{References}

1) Health and Welfare Statistics Association (2005) The present occupational health state. In: Health and welfare statistics association, Health and Welfare Statistics Association (Ed.), 292-4, Tokyo.

2) Rogers B (1998) Occupational health nursing expertise. J UOEH 20 (Suppl), 1-10.

3) Isono F (1997) Job conditions and the current conception of occupational health nurses in industries having fewer than 1,000 employees. San Ei Shi 39, 203-8 (in Japanese with English abstract).

4) Ikushima M, Ishihara I, Kawamoto R (2002) A survey of public health nurses regarding their awareness of the abilities, skill and knowledge necessary to fulfill an occupational health nurse's role, and proposal of a new curriculum for occupational nurse specialists at the master level. J UOEH 24, 313-25 (in Japanese with English abstract).

5) Inoue M, Yamamoto S, Kan H, Tateishi H, Harada N (2004) Occupational health nurses' participation in health committee surveyed in Yamaguchi prefecture, Japan. Ind Health 42, 287 91.

6) Isono F (2001) Actual duties and cognition of roles for occupational health nurses. Kangogakuzasshi 65, 250-4 (in Japanese).

7) Isono F (2003) The expectations of enterprises for occupational health nurses. San Ei Shi 45, 50-6 (in Japanese). 